body," and Dr. Lucas further points out that Dr. Parkes thought "fresh, and especially raw, meat useful in scuryy, and this is conjectured to be from its amount of lactic acid." Now, whilst these statements prove my position with regard to the view that $I$ have advanced, that scurvy is induced through dimivished alkalinity of the blood, they are fatal to the suggestion I uffered, that the inferiority of hung to fresh meat as an antiscorbutic is due to the presence of lactic acid, the resulc of muscle decomposition after rigor mortis and the increase of acid salts in the blood. A litile consideration will show, however, the two views can be brought into harmony.

It is quite true that lactic acid goes to form alkaline carbonates in the body; but, then, what form do the carbonates take? If the base and acid are in due proportion, we may have the normal carbonate $\left(\mathrm{Na}_{2} \mathrm{HCU}_{3}\right)$, an alkaline salt with an alkaline reaction. This, most probably, is the condition in which the alkaline carbonates are formed in the living body, whilst the lactic acid formed in the muscle passes out into the circulation, and fre:h portions of the base are being brought into contact for it to combine with. But, on the other hand, if the acid be in exces: then we have an acid carbonate $\left(\mathrm{NaH}_{2} \mathrm{CO}_{3}\right)$, the bicarbonate, an acid salt which, though it has an alkaline reaction, has the effect of an acid, since with neutral salts in the blood it is capable of forming acid salts with acid reactions. It is probably this form of carbonate which is derived from the lactates formed in muscles by decomposition after death, since the lactic acid is not carried off as soon as it is formed into the circulation; nor can a fresh supply of alkali be brought to it for it to combine with, so that acid lactates will in turn be reduced to acid carbonates. Again, free lactic acid developed from muscle in forming a lactate must take the base from some other salt, unless we assume that potash or soda exists uncombined in the tissues. The salt that is apparently robbed, as far as expeiment enables us to judge, is the neutral phosphate of soda or potash. Lactic acid deprives this of cne atom of its base, forming a lactate, but converting the neutral phosphate into acid phosphate. I may add that Maly has determined the presence of both acid sodium phosphate and acid sodium carbonate in blood.

Dr. Parkes' assumption, therefore, that fresh meat is antiscorbutic on account of the presence of lactic acid, is not opposed to my hypothesis that preserved or hung meat loses its antiscorbutic virtues owing to the development of this acid ; since, as stated above, in the one case a small quantity of lactic acid and a sufficiency of base lead to the formation of alkaline salts, whilst in the other excess of acid and deficiency of base cause the formation of acid salts.

I am, Sir, yours obediently, CFARLES HENRY RALFE.

Queen Anne-street, W., Nov. 28th, 1882 .

\section{SPINA BIFIDA.}

To the Editor of THE LANCET.

SrR,-In your issue of November 18th there appears a report of a discussion on the subject of spina bifida before the Clinical Sosiety of London, and I am gratified to notice that some cases successfully treated are mentioned. My object in noticing the discussion is not to criticise the remarks of any of those who took part in it, but rather to name one or two observations or reflections which an increased experience has enabled me to make. Let me state in limine that $I$ never treat a case without previously informing the parents of the extreme danger, and of the possibility of even instant death, and my assistants are instructed in regard to the certainty of a fatal result if the cerebro-spinal fluid is allowed to drain away.

It is now my impression that many cases are lost from delay in the treatment; the tumour grows, and thus the interior presents a much greater surtace, so large in fact that the infant's feeble powers are unable to bear up against the local excitation requisite to effect a cure, and exhaustion follows. Pressure also, but very gentle pressure, ought to be useful in dealing with the larger tumours. Again, although very many lumbar cases have been successful, I am satisfied that the injection ought to be made with greater care than usual in low lumbar, or those almost coccygeal. This is the opposite of what might be expected, but from dissection I have learned that there the openings into the spinal canal are often large, allowing the injected fluid to run further than is desired, and the shock is thus apt to be greater and more immediate.

In respect to hydrocephalus, it will occasionally occur in such cases, yet the history of at least two cases known to me, shows that there was a threatening of hydrocephalus betore operation, which aiterwards permanently disappeared as the patients are still alive and well. After injecting a spina bifida we should wait usually three weeks, longer if the tumour seems to be shrinking. The necessity for earlier interference might arise from circumstances too varied to be noticed here.

One case of meningocele was presented to me, which I injected not fewer than eight times with a solution of double strength (twenty grains of iodine and sixty grains of iodide of potassium in an ounce of glycerine), and which became perfectly consolidated. Nearly two years thereatter the child died of bydrocephalus.

I have been much pleased with the numerous successes of which, from time to time, I have been iuformed (now about forty), and my object in now writing you, is to lead, if possible, to greater security in an operation so critical.

Glasgow, November 20th, 1882

1 am, Sir, yours faithfully, JAMES MORTON.

\section{ON THE DISTRIBUTION AND GERM ORIGIY OF CANCER.}

\section{To the Editor of THE LANCET.}

SIR,--In the year 1875 attention was afresh directed to the geographical distribution of disease by the lectures of Haviland. Turning to one of the maps by which they were illustrated, that on cancer, we find that each bank of the Tweed about Berwick, of the Tyne at Newcastle, of the Swale, the Ouse, and the Humber in Yorkshire, the Trent about Nottingham, and the whole of our beautiful Lake districts are most fertile beds of cancer. Wales is nearly free except about the Conway and the Dovey; so are the manufacturing districts. Whilst Chester, Shrewsbury, Derby, Newark, and Lincoln ave bad ; as are, also, parts of Broningham, the towns of Nuneaton and Lutterworth, and Huntingdonshire, Norwich, Stamford, and Peterborough, Cornwall is comparatively free except in the neighbourhoods of Falmouth and Bodmin. A belt of liability runs across Devonsuire from Barnstaple to Exeter and Exmouth. Ply. mouth and the vicinity, with Totnes, is above the average; as, also, are Taunton, Axminster, and Bridport, Wells, Warminster, Blandford, and Poole in Dorsetshire. Bath stunds high for mortality from cancer; so do Tetbury, Marlborough, Devizes, Shaftesbury, and Lymington. The Isle of Wight is all but free from cancer; and so is, likewise, the New Forest. Brighton and its district are bad; so are Hastings, Romney Marsh, Folkestone, Dover, Deal, Ramsgate, and Margate. Coming nearer to the metropolis, we find that in Chertsey, Guildford, Dorking, Epsom, Reigate, and East Grinstead cancer is pretty equally prevalent. The huge London district, with the exception of Uxbridge and Hendon, if we extend it to Oxford and Ayles. bury, with St. Albans on the one side, to Ware, Epping, Ongar, and Shoeburyness on the other, constitutes one appalling cancer field. In London proper, strangely enough, the parish of St. Luke's, the swarming neighbourhood of Bishopsgate, crowded Bethnal Green, far away Old Ford, Bow, Puplar, the Isle of Dogs, savoury Rotherhithe, and frdgrant Bermondsey, are almost entirely exempt. The west, the north, the south as far as Wandsworth and Clapham, have a second degree of mortality; the parts about the Marylebone-road, Regent's-park, and Primrose-hill are ex. ceptionally bad. The returns for London go to show what is demonstrable in another way-that aensity of population, hard living, and laborious toil have very little to do in favouring the appearance and growth of cancer. Liverpool, like London, is situated on the banks of a large tidal river; it has a teeming and not over-sober population; its deaths in 1878 from all causes out-numbered by a thousand the total of its births; and yet it, with this heavy general mortality, has an enviably small percentage of deaths from cancer. The reason being that it is surrounded by a district not liable to cancer-one, in fact, affording the lowest mortality from this cause. On the con. trary, London is a huge cancer-bed in itself, and at every 
conceivable point the country for many miles round is almost equally bad. From thesefacts Haviland deduces the following conclusions :-All places and districts with a high mortality from cancer present common characteristics. They have rivers or streams taking their rise in soft, crumbling rocks ; the volume of water is liable to overflow after violent rains or sudden thaws, submerging the country to a greater or less extent on either side. The subsidence of these floods is very much more gradual than the rapidity with which they spread. Hence a complete saturation of the soil to a considerable depth, and from the surface a constant exhalation of decaying vegetable and organic matter. The land having never time to purge itself from the poisonous malaria thus engendered, has a store constantly in hand with which to welcome the next deadly overflow. Hence, I would submit, that it follows incontestably that cancer beds, once formed in this fashion, must go on in an ever-increasing ratio in the manufacture, propagation, and dissemination of germs which are the sole efficient cause of cancer.

If this theory, which I contend the logic of facts establishes, be correct, it throws much light on the increase of cancer, its apparent hereditary nature, its liability to return, and preponderating influence amongst females, whilst it affords some hope of successful treatment.

I am, Sir, yours obediently,

Brook-street, W., Nov. 6th, 1882. R. S. GUTTERIDGE, M.D.

\section{DEATH AFTER ABDOMINAL OPERATIONS FROM HEART-CLOT, DUE TO DISEASE OF THE KIDNEYS.}

To the Editor of THE LANCET.

SiR,-In The LANcet, November 25th, 1882, Mr. Lawson Tait asks "help from those who are familiar with kidney troubles." I doubt if he will find anyone who can help him to diagnose these granular kidneys before operation; or who can teach him how to prepare the patient so as to avoid possible evil results from their presence. I will, however, venture to tell him how to avoid such deaths as he describes. Let Mr. Tait protect his patients from sepsis during the operation, and he will avoid these deaths "in thirty-six hours from heart-clot," which simply mean deaths from acute septicæmia, or septic intoxication. "The details of the operations were found to be quite satisfactory." Why? Because the poisoning is so rapid that all secretion and excretion is checked, and all the vital processes are in abeyance. If the patients lived long enough septic peritonitis, pleuritis, \&c., would develop, and we should not find the details of the operation so satisfactory. If Mr. Tait will consult Mr. Spencer Wells' admirable ovariotomy tables, he will find plenty of such cases as he records, but the deaths are not attributed to the diseased kidneys. The deaths are due to the disease of the kidneys, but only indirectly so. The septic virus is the real cause of death; the diseased kidneys cannot eliminate it, and the patients are poisoned right off with it; whereas if their kidneys had been healthy much of the poison would have been eliminated, and they might have struggled through, or died later with distinct post-mortem evidences of the septicæmia. The rapidly-ascending pulse is the characteristic feature of the condition; high temperature may be absent, or the temperature may even be subnormal; the poison acts too quickly and violently for the development of the tissue changes which cause high temperature.

It has become the fashion with those who discard Lister. ism to attribute all their mortality after operation to diseased kidneys. First it was the carbolic acid which caused fatal nephritis, or overworked these diseased kidneys. Now the carbolic acid has been sent to the right about, and still the patients with diseased kidneys die ; so it is only the kidneys that cause death. I do not deny that carbolic acid recklessly used may cause death with these diseased kidneys or even without them; but I affirm that all evidence is in favour of the septic virus being the greatest danger to patients with diseased kidners. Some time back I called attention to the fact that in spite of Listerism, patients who have been tapped will die of septicæmia. Mr. Tait would have none of it, but now he comes forward and in his own practice demonstrates the association between tapping and death after ovariotomy from heart-clot, which is simply death from septicæmia, as everyone with sufficient experience in abdo- minal surgery knows. Perhaps Mr. Tait can tell me why he and those who agree with him, with regard to Listerism, are so afraid to admit a death from septicæmia.

I am, Sir, yours faithfully,

J. KNOWSLEY THORNTON.

Portman-street, W., November 2 th, 1882.

\section{"SHOULD DISEASES OF CHILDREN BE MADE A SPECIALITY AT OUR GENERAL HOSPITALS ?"}

To the Editor of THE LANCET.

SIR,-Mr. Churchill's letter and your remarks thereon bring prominently forward the remarkable fact that by far the majority of those who leave our medical schools at the present time, to face the responsibilities of general practice, leave with a very inadequate knowledge of the diseases of children, although in all probability the major portion of their first patients will consist of children. Possibly under the idea that the greater includes the less, or that opportunities of frequenting the out-patient room of a children's hospital are not readily afforded, and do not pay from an examination point of view, they never familiarise themselves with the clinical examination and treatment of children whilst students, and find out their error only when fairly launched upon general practice. It is beyond all doubt a fact that not only the average student, but by far the majority of the men who have held the most valued resident posts at our large hospitals, leave to enter upon practice unfamiliar with the ordinary complaints of childhood, and are completely at sea in the matter of prescribing medicine or a diet for a child. To take one familiar instance: How many children are sent into a fever hospital in the course of a year suffering from acute pneumonia, the sender unfamiliar with the facts, that croupous pneumonia in children as often attacks the apex of the lung as the base, that it is frequently attended with delirium, and that the classical physical signs may be latent or may never appear. In some cases, no doubt, men have the means and the wisdom to take a clinical assistantship or housesurgeoncy at a children's hospital or dispensary before entering upon private practice, but this can only be the privilege of the few; the majority will still be dependent upon the clinical instruction to be derived from lectures and visits to the out-patient room or wards of a children's hospital or special department of a general hospital. How is it possible to facilitate the study of children's diseases at our medical schools? I have often been struck by the absence of any questions on diseases of children, except, perhaps, one or two stock ones, in the medicine papers set by the various examining boards; no one wishes for a separate examination paper, but surely, considering the importance of the subject, it should fairly claim a fair share of attention. Why, also, will not the examining boards recognise three months spent in attending the practice or filling the post of clinical assistant at a children's hospital, as they do at a lunatic asylum, to count as part of the time devoted to clinical study? I must confess, Sir, too, that I cannot agree with you when you deprecate the giving of a course of systematic lectures on diseases of children. No one doubts that the multiplication of lectures is a weariness to the flesh; but surely a course of, say, ten or twenty lectures on a subject that bears so closely ou the daily work of every ordinary practitioner would be at least of equal value to the courses regularly delivered on botany, comparative anatomy, toxicology, or lunacy? Need there be any real severance of the course from that of systematic medicine because given by a second person whose daily work renders him specially familiar with the subject? The classical lectures of Watson and West are found, or ought to be, side by side on the shelf of every practitioner: would anything be gained by binding them up together? Surely the lecturer on medicine will not feel himself aggrieved becanse he is relieved of the necessity of discoursing on diseases incident to birth, or on the athrepsia of infants or even congenital sy philis or whooping-cough? While, on the other hand, it would be absurd for the children's course to cover the whole ground occupied by pneumonia or typhoid ferer because they both happen frequently to occur in cbildhood. If these lectures are illustrated by clinical teaching in the out-patient room and wards, I cannot but think that they would be productive of 